\title{
Derangements in Coronary Calcium Score and Left Ventricular Global Longitudinal Strain in Patients Post Left Breast Radiotherapy
}

\author{
Andres Palomo \\ Beaumont Hospital \\ Thelma Dangana \\ Rush University Medical Center \\ Anel Yakupovich \\ Rush University Medical Center \\ Sanjib Basu \\ Rush University Medical Center \\ Ibtihaj Fughhi \\ Rush University Medical Center
}

Tochi Okwuosa ( $\square$ tokwuosa@rush.edu)

Rush University Medical Center https://orcid.org/0000-0001-7666-1217

Short communication

Keywords: breast cancer, coronary artery calcium score, global longitudinal strain, radiotherapy

Posted Date: February 24th, 2020

DOl: https://doi.org/10.21203/rs.2.24279/v1

License: (9) This work is licensed under a Creative Commons Attribution 4.0 International License. Read Full License 


\section{Abstract}

Background

Radiotherapy is a common treatment for breast cancer, with unintended long-term CV consequences; and no consensus on adequate CV screening methods to prevent future events. We aimed to assess the use of coronary artery calcium (CAC) and left ventricular global longitudinal strain (GLS) to identify those at risk for CVD due to radiotherapy.

Methods

Using data from an urban cancer registry, we enrolled 17 women (mean age 62 years) with left-sided breast cancer from 1999-2003, treated with radiotherapy. Agatston CAC score was measured by CT scan; and GLS by echocardiography. Logistic regression was used to compare study CAC scores with historical controls using age- and race-matched (Multi-Ethnic Study of Atherosclerosis) MESA CAC calculator [derived from MESA cohort from 6 US communities, free of clinical CVD at baseline (2000-2002) https://www.mesa-nhlbi.org ]; and GLS with historical controls from prior meta-analysis with defined normal GLS values ( Yingchoncharoen et al).

Results

The Hosmer-Lemeshow goodness of fit test reported a significant lack of fit $(p<0.02)$ compared with the expected probability of non-zero CAC in the historical controls from MESA. The mean GLS of $-20.6 \%(95 \% \mathrm{Cl}-21.50 \%,-19.79 \%)$, and was not statistically different when compared with the average of the historical controls. However, there was a significant difference of GLS compared to the meta-analysis using a onesample $T$ test with $P=0.03$.

Conclusion

We found that women post left sided breast radiotherapy had higher CAC presence without significant difference in mean GLS, compared with historical controls from the MESA database and prior GLS meta-analysis.

\section{Introduction}

Breast cancer remains the most common cause of cancer in women [1], and due to recent advances in treatment with adjuvant chemo- and radiotherapy, women with breast cancer are living longer. As women are surviving breast cancer, the treatment modalities cause significant cardiovascular morbidity such that heart disease remains the most common cause of death outside of malignancy in these women. [2].

Chest wall radiation is a common adjuvant treatment in women with breast cancer. In cases of left-sided breast cancer, external radiotherapy to the heart is common and often unavoidable due to the location on the chest wall [3]. Non-contemporary radiotherapy techniques, such as those used in many current cancer survivors, involved electron beam radiotherapy with higher radiation doses. [4] Such techniques induced heart disease in approximately $50 \%$ of patients post chest wall radiotherapy; with risk of developing heart disease occurring prior to or by 5 years post treatment, and even upwards of 30 years. [5]

Screening for coronary heart disease (CHD) remains a clinical burden in the general population and has yet to be fully validated for breast cancer patients after receiving radiotherapy. [5] Coronary artery calcification (CAC) can be detected with cardiac computed tomography (CT) and is quantifiable by Agatston scores. CAC scoring has been shown to have one of the highest sensitivities for risk stratification and has significant prognostic implications for CHD risk beyond traditional Framingham risk factors, especially in those who may be asymptomatic at intermediate risk [6].

Speckle tracking trans-thoracic echocardiography (STE) is a newer echocardiographic imaging technique that is used to assess left ventricular (LV) myocardial global longitudinal strain (GLS). GLS measures LV myocardial regional deformation as a marker of contractility and elasticity, [7] and measures deformation along the LV wall with shortening during LV contraction. Furthermore, GLS has been shown to precede changes in LV ejection fraction (LVEF) as it allows differentiation of active and passive movement of myocardial tissue, whereas wall motion evaluation by standard 2D echocardiography cannot. [7]

The goal of this study is to further characterize the use of CAC screening and GLS as screening tools for heart disease in breast cancer survivors post exposure to left-sided chest radiotherapy by non-contemporary techniques. This would allow for further risk stratification in cancer survivors; to focus on early prevention and treatment of heart disease as a cause of cardiovascular morbidity and mortality in this highrisk population.

\section{Methods}


We included 278 women diagnosed with breast cancer between 1999 and 2003, ages 18-79 years, treated with radiotherapy and identified from the Rush University Medical Center (RUMC) Cancer Registry. The study was approved by the RUMC institutional review board and informed consents were obtained from study participants. Exclusion criteria were women with isolated right-sided breast cancer, metastatic disease at diagnosis, recurrence of disease, patients with end-stage renal disease, patients with known/prior CHD, and patients with any metal used for surgery within the chest wall. The study participants were invited to RUMC to undergo CT scans and STE for CAC and GLS assessments, respectively.

A total of 17 participants responded to the invitation to participate in the study. The mean age of participants was 62 years, range $55-69$ years. Races were $76 \%$ white, $12 \%$ Black/African American, $6 \%$ Hispanic. Among traditional Framingham cardiovascular risk factors: $41.2 \%$ of women had hypertension, $29.4 \%$ with diabetes, and $41.2 \%$ with dyslipidemia. $35 \%$ were former smokers, while $47 \%$ were never smokers, and $6 \%$ were current smokers. We assessed exercise intensity: $6 \%$ of women never exercised, $47 \%$ achieved $3-6$ metabolic equivalents (METs), and $35 \%$ achieved > 6 METs on a weekly basis.

Table 1 describes the individual patient variables for the cancer treatment and results of CAC and GLS. All participants received left-sided breast radiotherapy, while $71.4 \%$ received adjuvant chemotherapy and $35.7 \%$ received anthracyclines. 
Table 1

Baseline Characteristics, Treatment history, values of Global Longitudinal Strain and Coronary Artery Calcification

\begin{tabular}{|c|c|c|c|c|c|c|c|c|c|c|c|c|c|}
\hline PID & AGE & RACE & BMI & CHEMOTHERAPY & $\begin{array}{l}\text { ENDOCRINE } \\
\text { THERAPY }\end{array}$ & DLD & HTN & DM & ARR & CAC & $\begin{array}{l}\text { CAC } \\
\text { REF }\end{array}$ & LVEF & GLS \\
\hline 1 & 56 & White & 30.6 & None & Tamoxifen & No & No & No & No & 0 & 28 & $\begin{array}{l}75- \\
80\end{array}$ & $\begin{array}{l}\text { Not } \\
\text { Reported }\end{array}$ \\
\hline 2 & 59 & White & 27.81 & CMF & $\begin{array}{l}\text { Tamoxifen, } \\
3 \text { Years }\end{array}$ & Yes & Yes & No & No & 0 & 34 & $\begin{array}{l}55- \\
60\end{array}$ & -18 \\
\hline 3 & 68 & Chinese & 40.5 & Unknown & $\mathrm{N} / \mathrm{A}$ & Yes & Yes & No & No & 1.1 & 51 & 72.5 & -20.4 \\
\hline 4 & 57 & White & 30.9 & AT & $\begin{array}{l}\text { Tamoxifen } \\
5 \text { Years }\end{array}$ & No & Yes & Yes & Yes & 0.3 & 30 & $\begin{array}{l}55- \\
60\end{array}$ & -20.5 \\
\hline 5 & 62 & White & 22.3 & None & Tamoxifen & No & No & No & No & 5.6 & 40 & 60 & -22.2 \\
\hline 6 & 61 & White & None & $\begin{array}{l}\text { Yes (unknown } \\
\text { type) }\end{array}$ & Unknown & N/A & N/A & N/A & N/A & 1.8 & 38 & $\begin{array}{l}55- \\
65\end{array}$ & -18.2 \\
\hline 7 & 69 & White & 36.7 & CMF & Tamoxifen & Yes & No & No & No & 0.9 & 56 & $\begin{array}{l}65- \\
70\end{array}$ & -22 \\
\hline 8 & 62 & White & 23.2 & AC, paclitaxel & Tamoxifen & Yes & Yes & Yes & No & 24.5 & 40 & 70 & $\begin{array}{l}\text { Not } \\
\text { Reported }\end{array}$ \\
\hline 9 & 57 & White & 30.9 & N/A & N/A & N/A & N/A & N/A & N/A & 45.6 & 30 & $\begin{array}{l}55- \\
60\end{array}$ & -19.4 \\
\hline 10 & 67 & White & 52.2 & N/A & N/A & N/A & N/A & N/A & N/A & 137.8 & 52 & $\begin{array}{l}55- \\
60\end{array}$ & Inaccurate \\
\hline 11 & 66 & White & 30 & $\begin{array}{l}5 \text { Cycles, Unclear } \\
\text { Type }\end{array}$ & No & Yes & No & Yes & Yes & 0.6 & 54 & 60 & 19.1 \\
\hline 12 & 61 & White & None & AT & No & Yes & Yes & Yes & No & 1578 & 38 & $\begin{array}{l}60- \\
65\end{array}$ & -20.3 \\
\hline 13 & 68 & Hispanic & 20.4 & AC, paclitaxel & Tamoxifen & Yes & Yes & No & Yes & 0 & 45 & $\begin{array}{l}55- \\
60\end{array}$ & -21.2 \\
\hline 14 & 63 & Black & 21.2 & None & N/A & N/A & N/A & N/A & N/A & 16.9 & 33 & $\begin{array}{l}55- \\
60\end{array}$ & -21.6 \\
\hline 15 & 58 & White & 23.7 & $\begin{array}{l}\text { Yes (unknown } \\
\text { type) }\end{array}$ & $\mathrm{N} / \mathrm{A}$ & N/A & $\mathrm{N} / \mathrm{A}$ & $\mathrm{N} / \mathrm{A}$ & $\mathrm{N} / \mathrm{A}$ & 0 & 32 & 60 & -22 \\
\hline 16 & 55 & Black & 28.6 & CMF, paclitaxel & N/A & No & No & No & No & 0 & 21 & 60 & -22.3 \\
\hline 17 & 69 & White & 27.4 & AC, docetaxel & $\begin{array}{l}\text { Tamoxifen, } \\
\text { Anastrozole }\end{array}$ & No & Yes & Yes & No & 0.2 & 56 & 60 & -21.8 \\
\hline $\begin{array}{l}\text { Abbr } \\
\text { arter } \\
\text { DLD } \\
\text { avai }\end{array}$ & slip & $\begin{array}{l}\text { AC, Doxor } \\
\text { tion score } \\
\text { mia; DM, d } \\
\text { patient ide }\end{array}$ & $\begin{array}{l}\text { icin, cy } \\
\text { AC REF } \\
\text { betes n } \\
\text { ificatio }\end{array}$ & $\begin{array}{l}\text { ophosphamide; AR } \\
\text { on-zero probability } \\
\text { litus; GLS, global }\end{array}$ & $\begin{array}{l}\text { arrhythmia; } A \\
\text { f coronary art } \\
\text { gitudinal stra }\end{array}$ & $\begin{array}{l}\text { Doxor } \\
\text { y calci } \\
\text { HTN, }\end{array}$ & $\begin{array}{l}\text { icin/ } \\
\text { sation } \\
\text { perte }\end{array}$ & $\begin{array}{l}\text { clitax } \\
\text { SMF, c } \\
\text { ion; L }\end{array}$ & $\begin{array}{l}\text { BMI, } \\
\text { slophc } \\
\text { EF, lef }\end{array}$ & $\begin{array}{l}\text { ody ma } \\
\text { phamic } \\
\text { entricı }\end{array}$ & $\begin{array}{l}\text { index } \\
\text { meth } \\
\text { r eject }\end{array}$ & $\begin{array}{l}\text { AC, cc } \\
\text { rexate, } \\
\text { n fract }\end{array}$ & $\begin{array}{l}\text { onary } \\
\text { uorouracil; } \\
\text { n; N/A, not }\end{array}$ \\
\hline
\end{tabular}

The statistical analysis included 17 participants. All completed the CT scan for CAC, while 14 of 17 completed STE for GLS. Control reference CAC values for these participants were obtained based on their age, gender and race using the Multi-ethnic Study of Atherosclerosis (MESA) database.[8] Observed values of any CAC (yes/no) were compared with the MESA database reported probability of having any CAC using a Hosmer and Lemeshow goodness of fit test. For STE, using confidence intervals and one-sample t-test, observed GLS values for the participants were compared with reported GLS summary statistics of historical controls from a prior meta-analysis of 2,597 patients. [9] Level of statistical significance was set a-priori to $p$-value $<0.05$.

\section{Results}

All 17 participants received left-sided breast radiotherapy and had preserved LVEF (range 55-80\%) - Table 1. The range of CAC score was 0 137.8; there was an outlier with CAC score of 1578 (Table 1). Nine (52\%) participants had CAC scores that fell within the less than minimal risk category. There was no significant asymmetry in the distribution of the measured CAC values from the corresponding control MESA median values (non-parametric Wilcoxon test p-value $=0.13$ ). However, 5 out of the 17 measured CAC values were zero. The Hosmer-Lemeshow 
goodness of fit test reported a significant lack of fit $(p<0.02)$ compared with the expected probability of non-zero CAC in the historical controls from MESA.

Fourteen out of 17 patients received STE for GLS, with mean GLS of $-20.6 \%$ (Table 1). The $95 \%$ Cl $(-21.50 \%,-19.79 \%)$ intersected with the confidence interval for the historical controls in the meta-analysis [9], $n=2,597$ (mean $-19.7 \%$; $95 \%$ Cl: $-20.4 \%$, $-18.9 \%$ ), suggesting no difference in GLS between the 2 groups. However, the GLS values of the participants showed a significant difference $(p=0.033)$ from the null value of $-19.7 \%$ (mean GLS in [9]) in a one-sample t-test.

\section{Discussion}

We found that women with a history of left-sided breast cancer whom received left sided non-contemporary breast radiotherapy had higher probability of CAC presence (defined a non-zero CAC value) compared with historical controls from the MESA database. However there was no significant difference in mean GLS in our study population compared to historical controls from a prior meta-analysis. Our study findings are noteworthy particularly because we still found significant differences in CAC between our study participants and the comparative historical controls despite the small number of participants in our study.

A recent study using MESA, has shown that both men and women with diagnosis of cancer had increased CAC when controlled for CHD risk factors.[10] This same study also showed that cancer patients have higher probability of CAC when compared with the MESA control group. We showed that left-sided breast radiotherapy with older techniques is particularly associated with elevated CAC. This suggests that CAC could possibly be utilized to appropriately triage post-radiotherapy breast cancer patients to a cardio-oncologist for further risk modification.

This study adds valuable information to the literature and is also unique in the assessment of GLS myocardial risk assessment in these breast cancer patients post chemo- and left-sided radiotherapy. We did not find significant differences in GLS between our study population and a prior meta-analytic study of historical controls, possibly alluding to absence of significant myocardial damage from left breast radiotherapy. However, we found significant difference between the mean GLS in our study participants compared with historical controls from the metaanalysis when the comparison was analyzed using a one-sample t test. Nonetheless, the small number of participants $(n=14)$ for our study possibly suggests the need for larger power to possibly detect effects of radiotherapy on GLS.

With further investigation in larger studies, the utility of CAC and GLS for CHD and cardiovascular disease screening in cancer patients post radiotherapy could be further established.

\section{Abbreviations}

CAC: Coronary Artery Calcium

CHD: Coronary Heart Disease

GLS: Global Longitudinal Strain

LV: Left Ventricle

LVEF: Left Ventricular Ejection Fraction

STE: Speckle Tracking Echocardiography

MESA: Multi-Ethnic Study of Atherosclerosis

MET: Metabolic Equivalent of Task

RUMC: Rush University Medical Center

\section{Declarations}

Availability of data and materials: The datasets used and/or analyzed during the current study are available from the corresponding author on reasonable request.

Declarations: The study was approved by the Rush University Medical Center institutional review board and informed consents were obtained from study participants 
Acknowledgements: The authors acknowledge the Rush University echo lab and radiology staff for their patience in coordinating and imaging these recruited research participants.

Sources of Funding: The study was funded by the Cohn Foundation Research scholarship fund

Competing Interests: None

\section{References}

1. Jemal, A., Siegel, R., Ward, E., Hao, Y., Xu, J., Murray, T., \& Thun, M. J. (2008)Cancer statistics, 2008. CA: a cancer journal for clinicians, 58(2), 71-96.

2. Howlader N NA, Krapcho M, Miller D, Bishop K, Altekruse SF, Kosary CL, Yu M, Ruhl J, Tatalovich Z, Mariotto A, Lewis DR, Chen HS, Feuer EJ, Cronin KA. SEER Cancer Statistics Review, 1975-2013. National Cancer Institute. April 2016. http://seer.cancer.gov/csr/1975_2013/.

3. Darby SC, McGale P, Taylor CW, Peto R. Long-term mortality from heart disease and lung cancer after radiotherapy for early breast cancer: prospective cohort study of about 300,000 women in US SEER cancer registries. The lancet oncology. 2005;6(8):557-565.

4. Vivekanandan S, Mhlanga J, Launders D, Przeslak A, Morgan DA. Beam angle manipulation to reduce cardiac dose during breast radiotherapy. The British journal of radiology. 2012;85(1011):265-271.

5. Lancellotti P, Nkomo VT, Badano LP, Bergler J, Bogaert J, Davin L, Cosyns B, Coucke P, Dulgheru R, Edvardsen T, Gaemperli O, Galderisi M, Griffin B, Heidenreich PA, Nieman K, et al. Expert consensus for multi-modality imaging evaluation of cardiovascular complications of radiotherapy in adults: a report from the European Association of Cardiovascular Imaging and the American Society of Echocardiography. Journal of the American Society of Echocardiography : official publication of the American Society of Echocardiography. 2013;26(9):1013-1032.

6. Polonsky TS, McClelland RL, Jorgensen NW, Bild DE, Burke GL, Guerci AD, Greenland P. Coronary artery calcium score and risk classification for coronary heart disease prediction. Jama.303(16):1610-1616.

7. Dandel, M., Lehmkuhl, H., Knosalla, C., Suramelashvili, N., \& Hetzer, R. (2009). Strain and strain rate imaging by echocardiography-basic concepts and clinical applicability. Current cardiology reviews, 5(2), 133-148.

8. Lakoski, S. G., Greenland, P., Wong, N. D., Schreiner, P. J., Herrington, D. M., Kronmal,A., ... \& Blumenthal, R. S. (2007). Coronary artery calcium scores and risk for cardiovascular events in women classified as "low risk" based on Framingham risk score: the Multi-Ethnic Study of Atherosclerosis (MESA). Archives of internal medicine, 167(22), 2437-2442.

9. Yingchoncharoen, T., Agarwal, S., Popović, Z. B., \& Marwick, T. H. (2013). Normal ranges of left ventricular strain: a meta-analysis. Journal of the American Society of Echocardiography, 26(2), 185-191.

10. Whitlock MC, Yeboah J, Burke GL, et al. Cancer and its association with the development of coronary artery calcification: an assessment from the Multi-Ethnic Study of Atherosclerosis. J Am Heart Assoc. 2015 